\title{
La escritura del arte en la primera etapa de la Revista Moderna
}

(4) Manuel Gutiérrez Silva

Universidad de Rice, Estados Unidos

\begin{abstract}
Resumen
Una de las prácticas menos entendidas de la Revista Moderna es la escritura del arte. A través de este género híbrido, que aparece en todos los números de la revista y toma un sin fin de formas experimentales (poemas en prosa, notas, reseñas, cuentos, ensayos, etc.), los modernistas se enfrentaron al arte moderno y a la nueva cultura visual que recién había arribado al país mexicano. Retomando el término escritura del arte (artwriting) del filósofo norteamericano David Carrier quien lo acuñó para referirse a la escritura creativa no-ficcional y ficcional empleada por poetas y novelistas para narrar sus encuentros con el arte visual, en este trabajo reviso el contexto historiográfico, cultural e intelectual que impulsó a este género para señalar el importante papel que tuvo en el esfuerzo de Revista Moderna para transformar el discurso académico que caracterizaba la discusión de las artes visuales en el siglo xix.
\end{abstract}

\section{Artwriting in the first stage of the Revista Moderna}

\begin{abstract}
One of the least understood practices to appear in the Mexico's Revista Moderna is artwriting. Through this hybrid genre, that appeared in all of the issues of the magazine and took on and endless array of forms (prose poems, notes, reviews, short stories, essays, etc.), the modernistas addressed their encounter with modern art and with the new visual culture that was arriving in the country at the turn of the century. Borrowing the term artwriting from the north American philosopher David Carrier -who coined the phrase to refer to creative non-fictional and fictional work written by poets and novelists about their encounter with art-in this paper I will review the historical, cultural and intellectual context that spawned the use of this genre. My aim is to show the important role artwriting played in the Revista Moderna's efforts to transform academic discourse about the visual arts.
\end{abstract}

Palabras clave

Escritura del arte Revista Moderna José Juan Tablada Manuel G. Revilla cultura visual

Keywords artwriting Revista Moderna José Juan Tablada Manuel G. Revilla visual culture 


\section{A escrita da arte na primeira etapa da Revista Moderna}

\section{Resumo}

Palavras-chave

Escrita da arte Revista Moderna José Juan Tablada Manuel G. Revilla cultura visual
1. Héctor Valdés (1967), Elisa García Barragán (2002) y Teresa del Conde (2007)
Uma das práticas menos compreendidas da Revista Moderna é a escrita da arte. Através deste gênero híbrido, que se faz presente em todas as edições da revista e toma mútiplas formas experimentais (poemas em prosa, notas, resenhas, contos, ensaios, etc.), os modernistas confrontaram a arte moderna e a nova cultura visual que, naquele momento, recém chegara no México. A partir da retomada do termo escrita da arte (artwring), proposto pelo filósofo americano David Carrier, e que faz referência à escrita criativa não-ficcional e ficcional empregada por poetas e romancistas para narrar seus encontros com as artes visuais, no presente trabalho faço a revisão do contexto historiográfico, cultural e intelectual que impulsionou o gênero, com o propósito de salientar o importante papel que desempenhou no esforço da Revista Moderna para transformar o discurso acadêmico que caracterizou a discussão das artes visuais no século xix.

Ha corrido mucha tinta en torno al arte visual que apareció en la Revista Moderna (1898-1903) y en la Revista Moderna de México (1903-1911). Sabemos por Héctor Valdés, Elisa García Barragán, Teresa del Conde y otros, que la revista en su larga trayectoria se convirtió en una especie de galería de arte, cosa que distinguía a esta publicación de sus antecesoras. ${ }^{1}$ Allí, sus lectores se transformaban en espectadores del emergente arte moderno nacional e internacional. Las cifras lo confirman por sí mismas. En la primera etapa de la Revista Moderna aparecen 54 artistas y 428 ilustraciones (Valdés, 1967). En su segunda etapa, se reproduce el trabajo de 111 artistas y 3334 ilustraciones. Estos números incluyen retratos, ilustraciones de textos, fotografías, viñetas, frisos, estampas y letras capitulares diseñadas por sus más asiduos colaboradores: Julio Ruelas (1870-1907), Germán Gedovius (1867-1937), Leandro Izaguirre (1867-1941) y Roberto Montenegro (1885-1967) (Clark y Defossé, 2002). Pero a estas cifras, ya impresionantes para la época, podríamos añadir aún más artistas (tanto históricos como ficticios) y obras (reales o imaginarias) que aparecen dentro de los ensayos, los cuentos, los poemas, las reseñas, las crónicas y las críticas de arte que se publicaron en ambas revistas. Esta escritura del arte es una de las prácticas que menos se ha estudiado o entendido del modernismo y, por ende, de la Revista Moderna.

\section{La escritura del arte: definiciones y distinciones}

Retomo el término escritura del arte (artwriting), del filósofo norteamericano David Carrier, quien lo acuñó hacia 1987 para referirse a la escritura creativa no-ficcional y ficcional empleada por poetas y novelistas para narrar sus encuentros con el arte visual (2003:4). A Carrier le interesaba distinguir entre la crítica de arte profesional o normativa que, en su opinión, había sido atrapada por los mecanismos del mercado del arte a finales del siglo xx, y este género hibrido, que se concebía como una descripción parcial de una obra de arte visual, a la vez que una narración acerca de la experiencia que esta produce en el espectador. Es decir, más que una crítica dedicada a la evaluación, clasificación, contextualización y análisis de las intenciones del artista, Carrier insistía en que solo la escritura que fuera conscientemente "persuasiva" y creativa en su forma y argumentación, podría aportar una alternativa para pensar el significado y el valor de objetos estéticos más allá de su mero valor económico. De esta forma, Carrier se oponía a pensadores como Noël Carroll, quien define la tarea de la crítica del arte como una "evaluación" que guía a "consumidores" al "valor" de una obra (Carroll, 2009: 46). Para Carrier, la escritura del arte tiene la misma importancia que 
los trabajos de reconocidos historiadores y teóricos del arte como Erwin Panofsky, Alois Reigel y Aby Warburg, ya que registra el impacto que una obra tiene en su público (Carrier, 2003:6).

La definición que ofrece Carrier es tan solo un punto de partida debido a que él no ha sido el único en reconocer la vitalidad y diversidad de la escritura del arte. En años recientes, artistas, teóricos e historiadores del arte han discutido la habilidad del género para pensar el arte visual más allá de la historiografía. La artista Cuco Fusco propone que la escritura del arte es una "práctica" que busca la "liberación de la imagen" y que emplea la escritura como una estrategia para problematizar al objeto artístico (Fusco, 2011: s/p). De acuerdo con Fusco, este géneroprocura borrar la división entre crítica y creatividad para hacer de la obra de arte un blanco de reflexión. La historiadora de arte Catherine Grant concuerda con Fusco y describe la escritura del arte como un género que, conscientemente, llama la atención sobre su proceso de creación literaria y reconstruye la experiencia física del acto de ver obras de arte (Grant, 2011). En otras palabras, este género favorece las posibilidades lúdicas del lenguaje y su capacidad de reproducir ante el lector el encuentro que ocurrió entre el escritor/espectador y un objeto artístico. De esa manera, la escritura del arte convierte la experiencia del espectador en el eje central de su propia creación; en ella ver y escribir se convierten en un mismo acto de creación.

Tomando en cuenta esas reflexiones sobre la escritura del arte contemporánea,podemos regresar a la Revista moderna y destacar dos aspectos importantes que han pasado inadvertidos para los estudiosos de ésta. Por un lado, dicho género hibrido aparece en todos los números de la revista y toma un sinfín de formas experimentales (poemas en prosa, notas, reseñas, cuentos, ensayos, etcétera) que requieren mayor atención de la que se les ha prestado. Aunque la historia del arte ha minado este género para extraer de él su información historiográfica o anecdótica, no se ha reconocido la calidad experimental ni su esfuerzo por aportar nuevas formas de concebir al arte visual. $^{2}$ Por otro lado, la revisión de la escritura del arte nos permite señalar vínculos entre la Revista moderna y diferentes prácticas contemporáneas para comprender su vigencia. En este trabajo me propongo pensar la escritura del arte de dicha publicación no como una crítica que solo aportó datos escuetos o fijos, sino que prestó atención a ésta como práctica que problematizó los discursos académicos entorno al arte visual de su época y que permitió una apertura creativa sobre cómo escribir y pensar acerca del arte.

\section{Transformaciones en la cultura visual de principios del siglo XX}

El trabajo que la Revista Moderna llevó a cabo para actualizar en México los cánones del arte y, en consecuencia, para renovar la forma en que se escribía acerca del mismo, coincidieron con cuatro importantes cambios en la cultura visual del país que se produjeron a finales del siglo xix y a comienzos del siglo xx. Por una parte, los avances de impresión transformaron la circulación y la forma en que se consumía la imagen. Por ejemplo, mientras surgía una pequeña clase media que reforzaba el consumo de bienes de lujo, fue en el Porfiriato cuando aparecieron las primeras campañas de publicidad que modificaron el paisaje urbano de la Ciudad de México. El historiador Stephen Bunker ha descrito cómo durante este período, la capital del país fue bombardeada con "imágenes de publicidad, iconografía y espectáculos" (Bunker, 2012: 55). A este cambio, debemos añadir que uno de los productos más anhelados por los nuevos consumidores fue, precisamente, la parafernalia óptica recién importada al país desde todas las esquinas del globo. Cabe recordar que, entre sus memorias, José Juan Tablada describe con entusiasmo el arribo del kinescopio, los estereoscopios y la cámara fotográfica (Tablada, 2010: 83-146). Tales adelantos en la impresión, en la circulación y en la capacidad de 
proyectar o capturar imágenes ampliaron la forma en la que se percibían el arte, la ilustración comercial y la fotografía. Como consecuencia de ello, la Academia de San Carlos y la Iglesia dejaron de ser los únicos espacios en los que se experimentaba la imagen. Los escenarios públicos y privados se convirtieron, para el espectador, en los lugares donde se podían observar reproducciones que aparecían a diario en periódicos, revistas, novelas populares, postales, folletos, álbumes de fotos y anuncios (Yuinovsky, 2011:s/p). La observación de estas pequeñas reproducciones pronto se convirtió en la principal forma de consumo de cultura, reeducando a una parte de la población y estimulando el deseo por los productos recién importados, así como por renovadas formas de decoración y de vestimenta (Gaitán, 2003).

Por otra parte, la experiencia privada de estas imágenes comerciales no solo produjo un público más informado sobre qué y cómo consumir, sino que también dio paso a un nuevo modelo de subjetividad. Beatriz González-Stephan señala que la proliferación de un nuevo sistema de visualidad en Latinoamérica al final del siglo xix creó una "nueva sensualidad" accesible a través de los "placeres de la mirada" (González-Stephan, 2003: 225-238). Es decir, la circulación de reimpresiones asequibles permitió a los espectadores gozar del placer de la observación del arte en espacios autónomos, cerrados y aislados. Esta nueva experiencia y este nuevo escenariode gozo íntimo contribuyó a la fascinación por aquel reino interior que, de acuerdo con Gerard Aching, fue el "tropo más utilizado" por los poetas modernistas. Este tropo se refiere figurativa y literalmente a aquellos nichos en los cuales "buscaban una prórroga de las arduas incertidumbres y demandas de la vida económica" y dieron expresión también a las "aspiraciones de la clase pudiente para cultivar el arte del placer" (Aching ,1997: 28). De esta suerte, tal y como interpreto la escritura del arte publicada por la Revista Moderna, ésta, tanto en forma como en fondo, modeló la mirada sensual que generó la proliferación de la cultura visual y el "reino interior" que describieron los modernistas. En sus páginas, los editores invitaban a sus lectores (ante todo a la minoría artística y a la élite cultural) a observar las obras de arte mexicanas, europeas y asiáticas a través de una mirada moderna, sensual y privada.

Un tercer aspecto en el cambio de la cultura visual de México recayó en que las asequibles reproducciones de arte generaron en la élite consumidora un afán por el arte internacional. Si antes los muebles de lujo y la arquitectura despertaban el interés de la clase media-alta, pronto la adquisición y apreciación de objetos de arte extranjeros, sobre todo franceses, alemanes y japoneses, supuso un símbolo de estatus y proveyó a los consumidores de un sentido de pertenencia al mundo moderno. La circulación de estas reproducciones de obras nunca antes vistas en el país, impulsó a algunos coleccionistas a exhibir sus nuevas adquisiciones en cafés y residencias, creando así las primeras exposiciones independientes de arte en la Ciudad de México. En consecuencia y según la historiadora cultural Shelley E. Garrigan, la popularidad y diseminación del arte en la prensa y la posibilidad de acudir y observar exposiciones de arte fuera de la Academia de San Carlos, pronto inspiró reacciones que se publicaron en los diarios y que sobrepasaron la crítica periodística, encargada hasta el momento de informar y evaluar el arte que se exponía tradicionalmente en esa institución (Garrigan, 2012: 44). Por lo tanto, a finales del xix, prosigue Garrigan, los críticos comenzaron a referirse al arte, como "la base en la que se construía el concepto de comunidad e identidad colectiva, calculando así el nivel nacional de degradación o desarrollo estético, y permitiendo a México un espacio en la modernidad y un estatus en la escala internacional" (Garrigan, 2012: 29). Debido a estas preocupaciones, concluye Garrigan, hasta finales del siglo xix, los comentaristas del arte oscilaban entre una mirada que gustaba de lo sublime y, otra más práctica, que buscaba el "valor" económico o social de la obra. La Revista Moderna reflejaba dichas preocupaciones en diferentes grados, pero respondía a ellas a través de una mirada particular y una forma de escritura creativa sin precedente en el país. Para los escritores de la publicación, 
el arte no era solamente un instrumento pedagógico o religioso, tampoco un mero objeto del mercado internacional -como propusieron críticos liberales como Ignacio Manuel Altamirano. Para los modernistas, el arte invitaba a convivir con él de otra forma, dado que representaba una especie de advenimiento al que tenían que atender con un rigor literario para extraer de la imagen una nueva forma del saber estético.

Por consiguiente, esta nueva forma de comulgar con el arte requería una distinta estrategia de escritura, aquella que indagara en el significado de una obra y que, a la vez, registrara la experiencia del espectador a través de una prosa individualista y original que se distinguiera del tono típico del emergente periodismo industrial. Este tipo de escritura se gestó tanto en México m en Europa a finales del siglo xix, periodo en el que se estrecharon con mayor firmeza los lazos entre las artes visuales y las verbales. La alianza impulsó un pensamiento interdisciplinario o indisciplinario (para tomar el neologismo de Rancière), que mezclaba discursos provenientes de la música, del teatro, de las artes visuales, de la literatura y de la ciencia (2006). En el caso de México, tal proceso se registró en escritores como Manuel Gutiérrez Nájera, quien en sus crónicas debía "partirse en mil pedazos y quedar entero", ya que el poeta se veía obligado a conocer todas las ciencias y todas las artes (Clark, 1998: 48). Para cronistas como Gutiérrez Nájera, la escritura debía ser una mezcla donde "géneros, temas, y lenguajes" eran partes integrales "de un todo que no se puede desmembrar sin riesgo de destruirlo". Como bien ha indicado Belem Clark de Lara, los modernistas buscaban una escritura que fuera un "espacio de convergencia" y "cruzamientos" (Clark, 1998: 68).

\section{La nueva estética, la Revista Moderna y Manuel G. Revilla}

Partiendo de la crónica najeriana, la escritura del arte que apareció en la Revista Moderna también se inspiró en la filosofía y en la estética del idealismo alemán y del simbolismo francés que los modernistas conocieron a través de tres pensadores importantes: Novalis, Nietzsche y Baudelaire. La filosofía de Novalis, incluyendo sus Himnos a la noche y Fragmentos, se comentó ampliamente en la primera etapa de la Revista Moderna. Novalis proponía una escritura sintética en donde el mundo visible se unía a la emoción y al pensamiento del espectador (Puja, 1900: 325-332). En la interpretación de Novalis que ofrece Maurice Puja, "el mundo antiguo con sus ideas y sus prejuicios propios, se desmembra" y el pensamiento moderno va "demoliendo" las creencias y las opiniones del siglo pasado (325). Ante esta transformación, Puja se detiene en los Fragmentos de Novalis como un modelo a seguir. Recordemos que, para Novalis, el fragmento como estrategia literaria y filosófica representaba un desafío a la división entre el arte y el pensamiento crítico, división central que sostenían Kant y Gottlieb Fichte. Para Novalis era importante ir más allá de esta distinción, proponiendo que el fragmento permitía utilizar los registros expresivos de la literatura para explorar la realidad de una forma distinta, uniendo así la expresión y el conocimiento, la sensibilidad y la razón. Puja cita puntualmente a Novalis: "Yo no puedo conocer nada sino cuando lo recibo en mí" (331). Esta unión entre el objeto y el sujeto se convierte en un proceso de exploración que se manifestará en la escritura del arte, reproduciendo así la unión entre espectador y obra.

De Nietzsche, los modernistas de la Revista Moderna tomaron una mirada crítica hacía la tradición académica y una renovada valoración del papel del arte y del artista en la época moderna. Las secciones del libro Humano, demasiado humano que aparecieron en la publicacióninstaban a una crítica que atacó "los vicios... de la moral" y los alertaba a que la excelencia artística alcanzaba su más alto grado cuando el artista no tenía "en cuenta el gusto reinante o la opinión general" (1900: 22). También, encontraban en estos aforismos una descripción de lo que debía hacer la "pintura literaria" o la descripción literaria de la pintura. Para Nietzsche un objeto obtendría su mejor 
interpretación cuando se extrajera del objeto mismo "sus propios colores" sin imponer valores ajenos a su propia materialidad. De esta forma, el cuadro comunicaría "su significado." Más claramente, ante una pintura, el escritor debía permitir que sus colores afectaran la forma en que se escribía acerca de ella para "hacer nacer al dibujo" dentro del comentario (1900: 26). Nietzsche reconocía que existía un diálogo profundo entre distintos creadores que la "pintura literaria", o lo que vengo llamando la escritura del arte, hacía visible.

Finalmente, en Baudelaire, los escritores de la Revista Moderna encontraron a un crítico que les pedía no confundir el lenguaje académico con el de la virtud, pero también atacar "las escuelas burguesas" porque creaban un arte de propaganda (1902: 265). Además, Baudelaire modelaba una crítica de arte abiertamente "parcial, apasionante, y política" e invitaba a los críticos a describir las obras de arte de forma seductora con las dolencias y los sufrimientos morales que toda obra llevaba consigo. Así, Novalis, Nietzsche y Baudelaire anunciaban las aspiraciones y los ideales de la Revista Moderna. Esta concebiría la escritura del arte de una forma fragmentada y aforística, que deseaba captar no solo los elementos formales, la moralidad o la ejecución genérica correcta o incorrecta de cualquier obra, sino también su forma y sus colores, pero también la sensación corporal e intelectual que éstos despertaban en el espectador.

Tal mirada activa, que se oponía a las ideas conservadoras que solo veían en el arte la representación de la moralidad o las concepciones liberales que abogaban por un arte nacionalista y comercial, apunta a lo que Julio Ramos ha llamado una voluntad de autonomía crítica. Es decir, al comenzar el siglo xx, los modernistas empezaron a "defender la especificidad del estilo" (2001: 65) como un rasgo fundamental del escritor moderno. El estilo expresaba el deseo del poeta moderno de afirmar su autoridad a través de una voz literaria única y de una mirada sensual y especializada. El estilo poético y la creatividad de la escritura del arte desafiaban al neoclasicismo y a la jerarquía de géneros que dominaban en la Academia de San Carlos.

Para entender el impacto que la escritura del arte de la Revista Moderna tuvo en el medio intelectual mexicano, solo tenemos que comparar su mirada con la del crítico del arte más importante del momento, Manuel G. Revilla. El mismo año que se fundó la revista, Revilla publicó un estudio sobre arte mexicano que resumía su concepción de la crítica del arte. En su ensayo "Las bellas artes en México en los últimos veinte años", Revilla declaraba la convicción de que la cultura la daba el clasicismo y la religión, alabando a la Academia de San Carlos "desde su fundación hasta hoy ya floreciente" (1999: 63). Como bien han visto Angélica Velázquez Guadarrama (2001) y Elisa García Barragán (2008) entre otras, Revilla confiaba en que la academia había custodiado el clasicismo y que, guiado por Pelegrín Clavé, había mostrado sus mejores dotes en aquellas pinturas de contenido religioso. En cambio, cuando Antonio Fabres (amigo de los modernistas) sustituyó a Clave, Revilla solo ofrecía críticas agrias. Para él, sin el apoyo de los mejores valores y tradiciones del pasado, el arte había entrado en un decaimiento irreversible.Escribe Revilla: "los modelos educan, forman el gusto y hacen por lo tanto puros, correctos, serios, clásicos, en una palabra, a fin de que el principiante adquiera sana doctrina..." (1999: 328). La prosa de Revilla es concisa, seca, y está llena de admoniciones. Revilla abandera la tradición, mientras que la modernidad le pasa inadvertida, no ofreciendo ningún comentario sobre el arte del presente.

\section{Cuatro ejemplos de la escritura del arte en la Revista Moderna}

Es ante esta forma de administrar el arte, en la que la Revista Moderna propone un amplio uso de distintas maneras y formas de registrar el arribo del arte moderno a México. En la revista, José Juan Tablada, Jesús F. Contreras, Ciro B. Ceballos, Amado 
Nervo, Manuel Ugarte, Rubén M. Campos y Jesús Urueta, entre otros, experimentaron con distintas formas de abordar al arte visual. Su escritura del arte se escapaba del rubro de la crítica revillana. A través de distintas estrategias narrativas o poéticas, pasando por el "reino interior" modernista que describimos arriba, y tomando las ideas estéticas de Novalis, Nietzsche y Baudelaire, encontramos perfiles de artistas decadentes, poemas en prosa dedicados a esculturas o pinturas europeas, versos que intentan excavar el significado de algún cuadro y "divagaciones" aforísticas y fragmentadas en torno al significado del arte en sí. Todas éstas emplean distintos elementos de la narrativa y poesía modernista y con frecuencia dentro de los mismos cuentos y poemas que aparecen en la Revista Moderna entrevemos comentarios, elogios, guiños, y críticas dedicados al arte moderno. En lo que resta de este artículo describiré algunos ejemplos de escritura del arte que nos permiten reconocer la riqueza de su diversidad y la fuerza de su experimentación.

El primer ejemplo nos revela la forma en que el arte visual se convirtió en un espacio para meditar sobre los nuevos derroteros estéticos de la época. En el poema en prosa escrito por Jesús Urueta, "Tarcisius", encontramos un homenaje a la escultura homónima del escultor francés Alexandre Falguière (1831-1900), que se hallaba en el Museo del Luxemburgo (1900: 294). Aquí, en vez de ofrecer al lector algún recorrido histórico de la obra o de clasificarla dentro de alguna tradición o Academia, al estilo de Revilla, Urueta toma la ocasión de celebrar los ideales modernistas y así contemplar al poeta modernista cómo mártir de la modernidad. Parado ante la escultura de un joven débil y derrumbado, Urueta escribe:

Morir así, como el joven mártir, lapidado el cuerpo y gozosa el alma!... apretar sobre el corazón la hostia santa mientras se cae al golpe impío!... ser el poeta, que al romperse, exhala su divino verso de piedad y de amor! (1900: 294)

Para Urueta, la figura del niño mártir, apedreado por una masa ignorante, ofrece un perfil solapado de los modernistas que habían sido marginados por su decadentismo. A la vez, este texto expone los rasgos poéticos de la escritura del arte que se encuentran en la Revista Moderna. Como este ejemplo encontramos varios, que son pequeños poemas en prosa que ofrecen descripciones de alguna obra desconocida por el público lector y las ideas que ésta inspira en el espectador.

Si el arte se convirtió en un espacio para meditar acerca de la modernidad, en él los escritores modernistas también encontraron una oportunidad para pensar lo literario más allá de la academia. Por ejemplo, Carlos Díaz Dufoo dirá más adelante, al comentar otra escultura, esta vez de Contreras, que para los modernistas "Nos era necesario un taller dónde educar a la literatura con los proteísmos de la línea... nos faltaba este contacto con la estatua, con el movimiento y la expresión de la forma" (1898: 119). El arte, como recomendaba Nietzsche, tenía la capacidad de afectar la forma misma de la escritura. Más allá de mera crítica o de proponer una descripción redundante de la escultura de Contreras o de Falguière, Dufoo y Urueta comparten los pensamientos que la escultura inspira en ellos y en sus colaboradores. Para ellos, el arte en general ofrece una educación que invitaba a la literatura a generar conexiones, convergencias, o cruzamientos, con otras obras y otros mundos.

Dado que la escritura del arte se proponía ir más allá de la estética académica, también servía para insertar a la cultura mexicana en un diálogo con el arte mundial. Otro ejemplo del tipo de escritura de arte que la revista publicó es el ensayo de José Juan Tablada titulado "El monstruo (fantasías estéticas)" (1899). En este, Tablada demuestra su apego a las ideas de Baudelaire y aborda uno de los temas predilectos del poeta francés. Tomando prestados recursos estilísticos y temáticos del poeta francés, Tablada se imagina una noche, hablando a la luz de su lámpara con una "silueta de formas 
indecisas" que le narra la historia del monstruo como figura, desde la Grecia clásica, pasando por Egipto, la Italia renacentista, la Alemania romántica hasta llegar al Japón de Hokusai. En todas estas etapas, el fantasma, en una especie de crónica en verso libre que va señalando distintas representaciones del monstruo, crea una galería de imágenes fragmentadas. De nuevo, Tablada no propone jerarquías estéticas, ni alguna moral o algún nacionalismo. Busca, a través de una prosa poética, la universalidad del arte, tema que encontramos en varias publicaciones, en las que indagó acerca del arte japonés, francés y mexicano.

\section{La escritura del arte modernista}

Ante la historia del arte practicada por Revilla, observamos en la escritura del arte de los modernistas un ejercicio especulativo. Es decir, estamos ante una escritura a la deriva, que se arriesga, ante el peligro de equivocarse, a inventarse una nueva forma de pensar el arte y de escribir acerca del mismo. Esta práctica no es una escritura disciplinada, con parámetros teóricos fijos, que al cabo de los años logrará cohesionarse y definirse como una nueva historia del arte, pero tampoco estamos ante la tradición revillana. En la escritura del arte encontramos fragmentos de experimentos de renovación y el cierre de antiguas ideas estéticas. Es el momento en que se derriba la retórica del siglo xix y se empieza a gestar otra, cruzada por distintas corrientes intelectuales y estéticas. Para los modernistas de la Revista Moderna, el arte mexicano de aquella centuria ya ha llegado a su clausura y emprenden una exploración de los nuevos rasgos del arte moderno. Experimentan, exploran, repiten, se revuelcan en una prosa sensualista, metafórica, pero no por falta de capacidades intelectuales. Es una escritura de experimentación ante la emergente cultura visual. Para los modernistas, el arte se convierte en proceso, y cada obra se multiplica ante la heterogeneidad de los significados que provoca. Los poetas modernistas ya no ven una obra como una definición, sino como una ramificación de múltiples caminos. La escritura del arte de la Revista Moderna genera redes de devoción, admiración, y diálogo.

La escritura del arte que vengo destacando pronto se impondrá en el campo cultural mexicano de una forma controversial, pero decisiva. En 1905, cuando Revilla entregó la primera parte de su catálogo y estudio del archivo de la Academia de San Carlos, el primero en la historia, Rubén M. Campos rechazó su publicación por parecerle "defectuosa y presuntuosa" sin las capacidades de "razonar un estudio de observación sutil que la academia habría de confiar a persona que reuniera conocimientos especiales en artes plásticas (...) con el buen gusto y que supiera reproducir sus opiniones en buen español, no en el que escribe en este catálogo" (Acevedo, Uribe, 1980: 15). El catálogo de la Revista Moderna cerraba así la crítica del arte del siglo xix, dando paso a una escritura del arte diversa y ágil, alejada de las preocupaciones religiosas o meramente monetarias o nacionalistas. Así, la Revista Moderna, con su galería, inauguraba una nueva relación que comprendía al arte y a su escritura como proyecto y proceso. Y al rebelarse contra el dogma académico y al adoptar métodos no-sistemáticos, la escritura del arte de la Revista Moderna logró crear lazos entre la experiencia de vida y la de la mirada. 


\section{Dibliografía}

" Acevedo de Iturriaga, E. y Uribe E.. (1980). La escultura del siglo XIX: Catálogo de colecciones de la Escuela Nacional de Bellas Artes. Manuscrito de Manuel G. Revilla. 1905. México, INBA.

" Aching, G. (1997). The Politics of Spanish American Modernismo. Cambridge, Cambridge University Press.

» Baudelaire, C. (1902). La literatura honesta. En Revista Moderna, año 5, núm. 17, $1^{\underline{a}}$ quincena de septiembre, pp. 265-266.

"Bunker, S. (2012). Creating A Mexican Consumer Culture in the Age of Porfirio Díaz. Albuquerque, University of New Mexico Press.

»Camacho Morfin, T. (2002). Imágenes de México: Las historietas de El Buen Tono de Juan B. Urrutia 1909-1912. México, Instituto Mora.

" Carrier, D. (2003). Artwriting. Writing About Visual Art. New York, Allworth Press.

"Carroll, N. (2009). On Criticism. New York, Routledge.

"Clark de Lara, B. (1998). Tradición y modernidad en Manuel Gutiérrez Nájera. México, UNAM.

"Conde, T. del. (2007). “El genial ilustrador de la Revista Moderna”. En El Viajero lúgubre: Julio Ruelas modernista. México, INBA, pp. 75-88.

»Díaz Dufoo, C. (1898). “La tentación. Boceto de una escultura”. En Revista Moderna, año 1, núm. 8,Noviembre, pp. 118-120.

»Fusco, M. (2011). “11 Statements around Art Writing”. En Frieze Blog,Frieze Magazine.

»García Barragán, E. (2002). "La plástica mexicana en la Revista Moderna de México". En Revista Moderna de México 1903-1911 Vol. Il eds. Clark de Lara, Belem y Fernando Curiel Defossé. México, UNAM, pp. 163-184.

" García Barragán, E. (2008). “Introducción”. En Justino Fernández, Pensar el arte. Ed. de Elisa García Barragán. México, UNAM, pp. vii-xxxv.

" Garrigan, S. E. (2012). Collecting Mexico: Museums, Monuments and the Creation of a National Identity. Mineapolis, University of Minnesota Press.

»González Stephan, B. (2003). "Showcases of Consumption: Historical Panoramas and Universal Expositions". En Beyond Imagine Communities, eds. CastroKlaren, Sara y John Charles Chasteen. Baltimore, Johns Hopkins University Press, pp. 225-238.

»Grant, C. (2011). “'A narrative of what wishes what it wishes it to be': An introduction to 'Creative Writing and Art History'”. En Art History, núm. 34, April, pp. 231-243.

》 Moyssen, X. (2009). La Crítica de Arte en México: 1896-1921, México, UNAM.

"Nietzsche, F. (1899). Humano, demasiado humano. En Revista Moderna, año 2, núm. 10, Octubre, pp. 300-304.

"Nietzsche, F. (1900). “Humano, demasiado humano". En Revista Moderna, año 3, núm. 2, $2^{\mathrm{a}}$ quincena de enero, pp. 21-27. 
»Ortiz Gaitán, J. (2003). Imágenes del deseo (1849-1939). México, UNAM.

"Puja, M. (1900). "Bosquejo de idealismo integral. Primeros ensayos sobre la filosofía de Novalis (Federico de Hardemberg 1772-1801)". En Revista Moderna, año 3, núm. 21, 1를 quincena de noviembre, pp. 325-332.

» Ramos, J. (2001). Divergent Modernities: Culture and Politics in Nineteenth-Century Latin America. Durham, Duke UniversityPress.

» Revilla, Manuel G. (1999). Las bellas artes en México en los últimos veinte años. En La crítica de arte en México: Estudios y documentos (1896-1913). Ed. Xavier Moyssén México, UNAM, pp. 63-74.

»Rancière, J. (2008). “Pensar entre las disciplinas: una estética del conocimiento. Traducción Alejandro Arozamena. En Inaesthetik, núm. o, Junio. En línea $<$ https://desarquivo.org/sites/default/files/ranciere_disciplinas_268.pdf >.

" Rancière, J. (2006). “Thinking between disciplines: an aesthetics of knowledge”. En Parrhesia, núm.1, s.p.

» Rodríguez Prampolini, I. (1997). La crítica de arte en México en el siglo xix. México, UNAM.

» Tablada, J. J. (2010). La feria de la vida. México, UNAM.

»Tablada, J. J. (1899)." El monstruo (fantasías estéticas)". En Revista Moderna, año 2, núm. 4, Abril, pp. 100-102.

»Urueta, J. (1900). “Tarcisius”. En Revista Moderna, año 3, núm. 19, 1ํㅡㄹ quincena de octubre, p. 294.

»Valdés, H. (1967). Índice de la Revista Moderna. México, UNAM.

»Velázquez Guadarrama, A. (2001.) Las biografías de Manuel G. Revilla y los estudios del arte académico. México, FCE.

»Yujnovsky, I. (2011). “Cultura y poder: el papel de la prensa ilustrada en la formación de la opinión pública”. En H-México, Mayo, s.p. 